\title{
A novel optical labeling scheme using a FSK modulated DFB laser integrated with an EA modulator
}

\author{
Zhang, Jianfeng; Chi, Nan; Holm-Nielsen, Pablo Villanueva; Peucheret, Christophe; Jeppesen, Palle
}

Published in:

Technical Digest Optical Fiber Communication Conference 2003

Publication date:

2003

Document Version

Publisher's PDF, also known as Version of record

Link back to DTU Orbit

Citation (APA):

Zhang, J., Chi, N., Holm-Nielsen, P. V., Peucheret, C., \& Jeppesen, P. (2003). A novel optical labeling scheme using a FSK modulated DFB laser integrated with an EA modulator. In Technical Digest Optical Fiber Communication Conference 2003 (Vol. 1, pp. 279-280). IEEE.

\section{General rights}

Copyright and moral rights for the publications made accessible in the public portal are retained by the authors and/or other copyright owners and it is a condition of accessing publications that users recognise and abide by the legal requirements associated with these rights.

- Users may download and print one copy of any publication from the public portal for the purpose of private study or research.

- You may not further distribute the material or use it for any profit-making activity or commercial gain

- You may freely distribute the URL identifying the publication in the public portal 
length converter," IEE Electron. Lett. 36, pp. 345 $347(2000)$.

[3] H. J. Lee, S. J. B. Yoo, V. K. Tsui and S. K. Fong, "A simple all-optical label detection and swapping technique incorporating a fiber Bragg grating filter," IEEE Photon. Tech. Lett. 13, pp. $635-637(2001)$.

[4] H. J. Lee, V. Hernandez, V. K. Tsui and S. J. B. Yoo, "Simple, polarization-independent, and dispersion-insensitive SCM signal extraction technique for optical switching systems applications," IEE Electron. Lett. 37, pp. 1240-1241 (2001).

This work was partially funded by the Defense Advanced Research Projects Agency (DARPA) and Air Force Research Laboratory under agreement number F30602-00-2-0543, by the National Science Foundation under grant number ANI998665 , and by the support of OIDA and Fitel Technologies.

TuQ5

5:45 PM

A Novel Optical Labeling Scheme Using a FSK Modulated DFB Laser Integrated with an EA Modulator

J. Zhang, N. Chi, P. Holm-Nielsen, C. Peucheret, P. Jeppesen, Research Center COM, Technical University of Denmark, Kgs. Lyngby, Denmark, Email: jz@com.dtu.dk.

The feasibility of an optical FSK labeling scheme is demonstrated. An optical signal consisting of a $10 \mathrm{~Gb} / \mathrm{s}$ payload and a $312 \mathrm{Mb} / \mathrm{s}$ label was generated, and its performance was evaluated in an $88 \mathrm{~km}$ transmission link.

\section{Introduction}

All optical label switching implements the packet routing and forwarding functions of multiprotocol label switching (MPLS) directly in the optical layer, which is a promising technology for next generation wavelength division multiplexing (WDM) networks. Several optical labeling methods have been proposed and demonstrated as possible solutions [1], in which the label is attached by time multiplexing or subcarrier multiplexing with the data payload. The optical label can also be achieved by angle modulation that is orthogonal to the intensity-modulated payload [2]. In direct detection system, the label information can be modulated using either the differential-phaseshift-keying (DPSK) or frequency-shift-keying (FSK) format. The feasibility of the optical DPSK labeling has been experimentally validated [3] However, this scheme imposes stringent requirements on the laser linewidth. The scheme of combined FSK/ASK modulation was demonstrated to be more applicable in practical netwotks [4]. In this paper, we report the construction of a novel optical FSK transmitter and investigation of the optical FSK labeled signal's performance. The generated signal consists of a $10 \mathrm{~Gb} / \mathrm{s}$ intensity modulated payload and a $312 \mathrm{Mb} / \mathrm{s}$ FSK format label, whose performance was evaluated in a $88 \mathrm{~km}$ standard single-mode-fiber (SMF) transmission link.

2. Operation Principle of the Optical FSK Transmitter

The optical FSK transmitter plays an important role in optical labeling. The label information is impressed upon the frequency of the optical carrier through FSK modulation, while keeping its amplitude unaffected. Thus the optically labeled packet can be achieved when the payload information is modulated on the amplitude of the carrier.

An optical FSK signal can be generated simply by directly modulating the electrical current of a DFB or DBR laser diodes [5]. However, the drive current variation also results in a simultaneous intensity modulation of the emitted light. As for the optical labeling, such residual intensity modulation has a detrimental effect on the optical packet when the payload information is added. To overcome this problem, we propose a novel optical FSK label generation scheme based on a commercially available integrated DFB laser/ electroabsorption (EA) modulator, whose configuration is shown in Fig. 1.

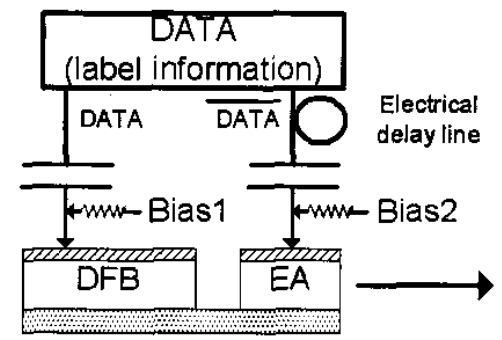

Fig. 1. Configuration of the optical FSK transmitter

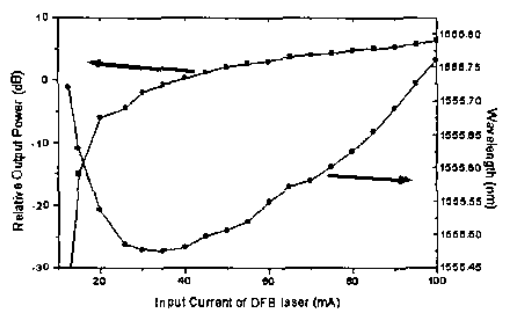

Fig. 2. (a) Characteristics of a DFB laser

In such a configuration, the DFB laser is driven with a bias current far above the threshold and a relatively small modulation current is added. The intensity variation of the laser output is then compensated through the integrated EA modulator driven with the inverse data. In this way, only the frequency modulation is expected in the final output of this integrated device.

The measured optical characteristics of the DFB laser/EA modulator are shown in Fig. 2 . The variation of injection current will change both output power and wavelength, as indicated in Fig. 2(a). In high bias current regime, a modulation current of nearly $30 \mathrm{~mA}$ is needed to achieve a $20 \mathrm{GHz}$ $(\sim 0.16 \mathrm{~nm})$ frequency deviation, which is accompanied by a $3 \mathrm{~dB}$ intensity variation. The integrated EA modulator shows a modulation efficiency of nearly $5 \mathrm{~dB} / \mathrm{V}$, as shown in Fig. 2(b). Both the DFB laser and the EA modulator have $3 \mathrm{~dB}$ modulation bandwidth of $2.5 \mathrm{GHz}$. Fig. 3 shows the measured eye-diagrams and optical spectrum of the FSK modulated signal when the DFB laser was driven with a $90 \mathrm{~mA}$ bias current and a $30 \mathrm{~mA}$ modulation current. Without intensity compensation, nearly $3 \mathrm{~dB}$ intensity fluctuation was observed, as shown in Fig. 3(a). Both the bias and modulation voltage of the EA modulator were optimized to compensate for the residual intensity modulation. The final output light had almost constant amplitude, as shown in Fig. 3(b) The perfect FSK signal with a peak-to-peak frequency deviation of $20 \mathrm{GHz}$ was finally generated, as indicated by the spectrum of Fig. 3(c).

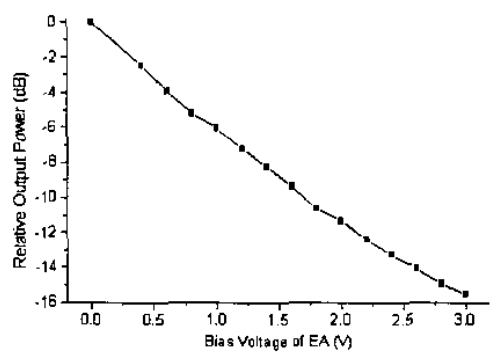

Fig. 2. (b) Characteristics of EA modulator

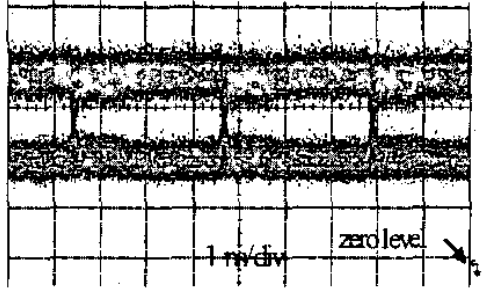

Fig. 3 (a) Direct output eye-diagram of the DFB Laser

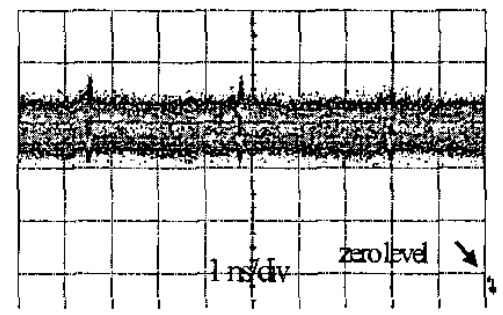

Fig. 3 (b) Output eye-diagram after EA compensation

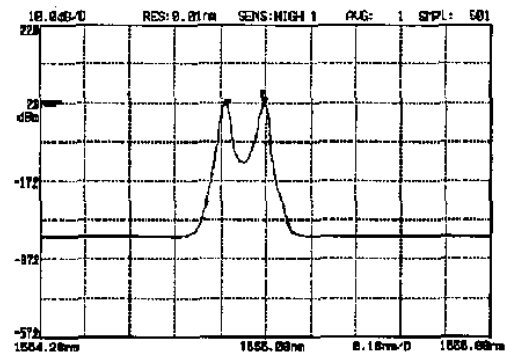

Fig. 3 (c) Output spectrum after EA compensation

\section{Performance of the Optical FSK Labeled} Signal

To investigate the performance of the optical FSK labeling scheme, an $88 \mathrm{~km}$ SMF transmission link was set up, as shown in Fig. 4. The optically labeled signal consisting of a $10 \mathrm{~Gb} / \mathrm{s}$ payload and a $312 \mathrm{Mb} / \mathrm{s}$ label was first generated, then transmitted over $88 \mathrm{~km}$ SMF, and finally detected using direct detection receivers.

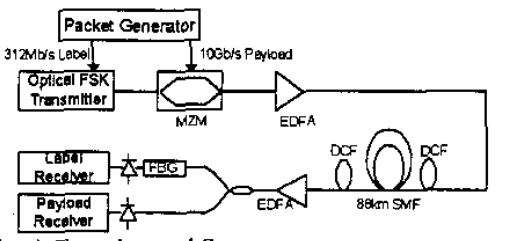

Fig. 4. Experimental Setup

Two pseudo-random pattern generators were used to generate the payload and label information. The label information was impressed upon the optical carrier $(1555.0 \mathrm{~nm})$ through FSK modulation, while the payload information was added by using a $10 \mathrm{~Gb} / \mathrm{s}$ Mach-Zehnder intensity modulator (MZM). The power of the labeled signal was amplified to $10 \mathrm{dBm}$ and input into the fiber. The transmission span consisted of $88 \mathrm{~km} \mathrm{SMF}$ and a matching length of dispersion compensating fiber (DCF). The DCF was inserted into the link based on a hybrid dispersion compensation map (i.e. split before and after the transmission fiber) to give optimized transmission performance. At the receiver node, the labeled signal was split using a $3 \mathrm{~dB}$ optical coupler. One arm was directly detected by a photodiode and thus the optical payload was converted into the electrical domain. In the other arm, a fiber-Bragg-grating (FBG) was used to filter only a single lobe of the FSK labeled 
signal, thus achieving the FSK demodulation. The demodulated label was received by an electrical receiver with $1.8 \mathrm{GHz}$ bandwidth. Fig. 5 shows the eye-diagrams of the payload and label.

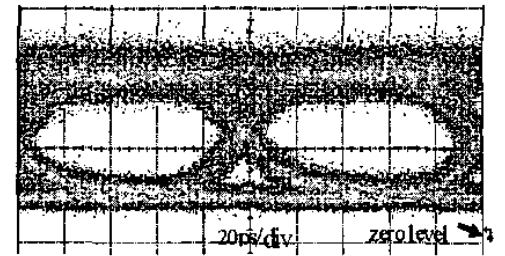

Fig. 5 (a) Eye-diagram of optically labeled signal

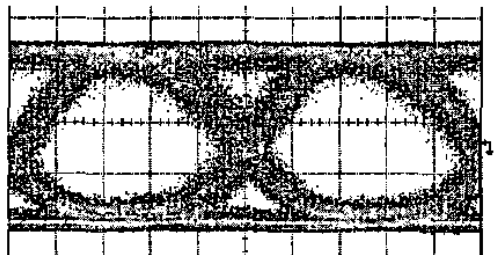

Fig. 5 (b) Eye-diagram of received payload (electrical)

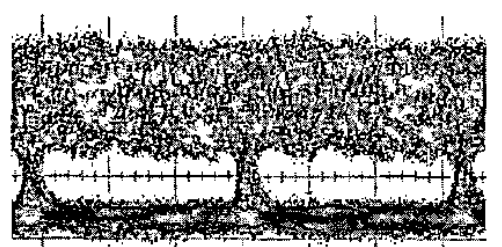

Fig. 5 (c) Eye-diagram of received label (electrical)

In the labeling scheme used, interference is introduced between the payload and label through the intermodulation distortion, as indicated in Fig. 5(c). The intensity modulation depth of the payload is a determining factor. Fig. 6(a) shows the relation between the measured receiver sensitivities of the payload and label and the extinction ratio of payload in the back-to-back case. A good trade-off between the label and payload performance can be achieved with nearly $6 \mathrm{~dB}$ extinction ratio. Fig. $6(\mathrm{~b})$ shows the transmission performance of the signal with $6 \mathrm{~dB}$ extinction ratio. The transmission penalties for label and payload are $2.2 \mathrm{~dB}$ and $1.2 \mathrm{~dB}$ respectively.

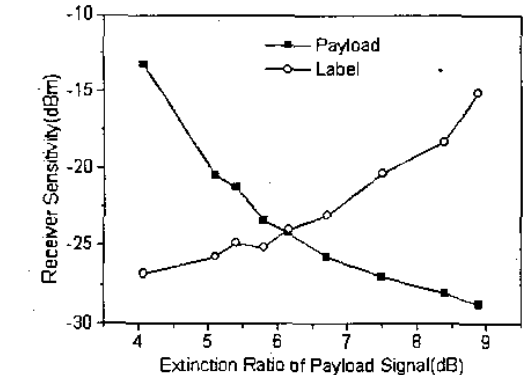

Fig. 6 (a)-Payload and label receiver sensitivity versus extinction ratio of the payload

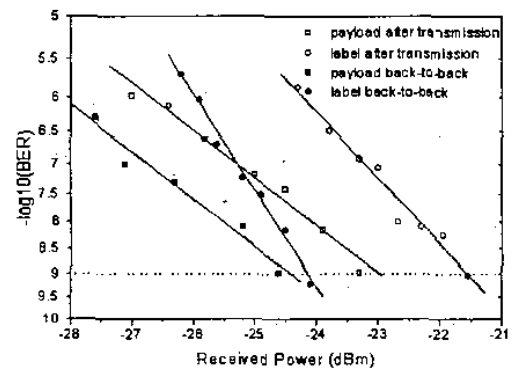

Fig. 6 (b) BER performance of the optically labeled Signal

\section{Conclusions}

We have proposed a novel optical FSK label generation scheme based on a commercially available integrated DFB laser/ EA modulator. An optically labeled signal consisting of a $10 \mathrm{~Gb} / \mathrm{s}$ payload and a $312 \mathrm{Mb} / \mathrm{s}$ label was generated. Both payload and label data could be recovered enror free after transmission over $88 \mathrm{~km} \mathrm{SMF}$, validating the feasibility of the optical FSK labeling scheme.

\section{References}

1. D. J. Blumenthal et al, "All-optical label swapping networks and technologies," J. Lightwave Technol., v18, 2058-2075 (2000).

2. T. Koonen et al, "Optical packet routing in IPover-WDM networks deploying two-level optical labelling," THL2.1, ECOC'01 (2001).

3. N. Chi et al, "All-optical transparent wavelength conversion of an optically labeled signal in ASK/DPSK orthogonal modulation," LEOS'02, MF3, (2002).

4. M. Hickey and L. Kazovsky, "Combined frequency and amplitude modulation for the STARNET WDM computer communication network," IEEE Photon. Technol. Lett., v 6, 1473-1475 (1994)

5. R. S. Vodhanel et al, "Performance of directly modulated DFB lasers in $10 \mathrm{~Gb} / \mathrm{s}$ ASK/FSK/ DPSK lightwave systems," J. Lightwave Technol., v8, 1379-1385 (1990).

TuR

4:30 PM - 6:00 PM Murphy 1

\section{Access Networks 1}

Gordon Wilson, Onetta Inc., USA, Presider

TuR1

(Invited)

4:30 PM

Whatever Happened to Fiber-to-the-Home?

N. Frigo, K. Reichmann, P. Iannone, $A T T$ Labs., Middletown,NJ,Email:frigo@att.com.

The early vision of FTTH, which promised abundant, ubiquitous, and future-proof bandwidth to consumers, has remained largely unrealized nearly 20 years after its birth. We discuss the historical, competitive, economic, and service reasons for this and prospects for the future.

\section{Introduction}

The vision of Fiber-to-the-Home (FTTH) was developed in the 1980's to satisfy the perceived need for future consumer applications. Optical fiber, it was felt, would permit high bandwidth transport, remove "bottlenecks" as video-rich services were developed, enable upgrades, and permit passive multiplexing that would remove remote powering costs. Various aspects of its history have been reviewed [1-3]. In today's terms, applications such as telephony and video-ondemand were to be carried over a B-ISDN universal carrier at OC-3 rates [1]. Proposals included an optical version of the telephony loop (each fiber carrying one house's circuit) to passive optical networks (PONs) with an optical splitter delivering light (and bandwidth) to several optical network units (ONUs). For Fiber-to-the-Curb (FTTC), the ONUs served several homes. In the nearly two decades since the FTTH/C vision was established, economic, regulatory, and technological forces have frustrated the vision's intended universal implementation.

The Recent Past

Fig. 1 shows some of the structural forces at work. The two major consumer applications today are broadcast television and telephony, which have nearly opposite characteristics. TV is a pas- sive impersonal entertainment delivered as a oneway service requiring high bandwidth. Telephony is personal communication that requires a twoway symmetric, low-bandwidth connection. We apparently value communication more than "content" [4] because the cost we pay per bit of information on phone calls exceeds that of entertainment by 6 or 7 orders of magnitude. TV's infrastructure is largely coaxial cable, with Multiple System Operators (MSOs) as service providers, while telephony is largely delivered over twisted wire pairs by Incumbent Local Exchange Carriers (ILECs). The two-way nature and quality of telephony makes aggregation, multiplexing, and switching essential, and thus the telephone and TV physical networks look quite different.

Both the MSOs and the ILECs have, over time, created efficient networks, and they can be viewed as vertically integrated: they own the networks that deliver their services. Both entities saw potential markets in the intermediate area of Fig. 1, labeled "Data," which could provide personal ized entertainment, be consumed as an end in itself, or enhance communications services. This seemed a natural extension for the ILECs, since these services required point-to-point connections, while regulatory and technical reasons prevented MSOs from entering. This space was intended for FTTH: the services would need more bandwidth than the copper plant allowed, and would need a new architecture, but revenues from new services such as Video on Demand (VOD) were expected to support a fiber build-out[1]

Developments in the 1980 s, however, changed the landscape dramatically. Advances in linear lightwave technology enabled CATV trunks with cascaded amplifiers to be replaced with high bandwidth, high fidelity optical analog transmission links to local nodes. The "pushing fiber deeper" approach became known as "Hybrid Fiber-Coax" (HFC), which, with its ability to shrink serving area sizes [5], began to look like the telco's FTTH/C plans, would permit the MSOs to carry data (albeit on a shared medium) This would crowd into the telcos' vision and could lead to competition in that new space. Meantime, technical advances in data compression reduced the information needed to carry video by nearly two orders of magnitude, and new modems with a variety of Digital Subscriber Loop (xDSL) formats were developed to carty data and video over copper pairs. Finally, user-friendly graphical interfaces made world-wide web traffic explode (making that central area in Fig. I look more attractive), launched the dot-com boom and CLEC threats. Technical advances also made Satellite TV a credible threat to cable, and Wireless phones a threat to landlines. Thus, technical progress and regulatory relaxations set the stage for that middle area to be actively contested while putting pressure on each market. What does the future hold?

Prospects for the Future

Overriding all of the plans, of course, is the need for the network to make money for its owner: early advocates estimated that the customer's willingness to pay for phone and VOD services would support a cost of $\$ 1500$ per subscriber for infrastructure [1] which is still a reasonable guess today. Much activity in fora and standards groups such as the Full Service Access Network (FSAN) and Ethernet in the First Mile (EFM) activities support the vision, and vendors are within striking range of these costs. Furthermore, there are several large trials run by ILECs (dating back to the 1980's), and some MSO trials have recently begun, so the players are developing technological experience. What are the prospects for a massive FTTH rollout? We believe that a major deployment is unlikely for the foreseeable future for several reasons.

First, the cost calculations require essentially monopoly conditions. The major cost of the FTTH network is in the installation of ubiquitous distribution fiber that permits a drop to any potential customer. This fixed cost of passing every customer must be borne by that fraction of customers who actually subscribe. If the "take rate" in a competitive market is $25 \%$, for example, then the effective cost per customer is nearly 4 times the 